\title{
A importância dos imigrantes e descendentes na seleção francesa ao longo das Copas do Mundo
}

\author{
The Importance of Immigrants and Descendants in the French National \\ Team throughout the World Cups
}

Guilherme Silva Pires de Freitas

Mestre em Filosofia, Universidade de São Paulo, São Paulo/Brasil gui_sp_freitas@yahoo.com.br

\begin{abstract}
Resumo: Conhecida pelo seu perfil multicultural, a seleção francesa de futebol contou com os serviços de diversos jogadores imigrantes e descendentes de imigrantes ao longo das Copas do Mundo. Este trabalho apresenta um histórico realçando a importância destes atletas que vestiram a camisa dos Bleus ao longo dos Mundiais desde os pioneiros como Alexandre Villaplane na Copa do Mundo de 1930 até a jovem geração multicultural bicampeã mundial em 2018, passando por Zinedine Zidane, maior ídolo do país e principal nome do título mundial em 1998. 0 artigo mostra ainda a importância e peso que o futebol tem para sociedade francesa, que através da modalidade consegue discutir e debater delicados assuntos de interesse nacional como a imigração, multiculturalismo e a identidade nacional.
\end{abstract}

PalaVRas-chave: Futebol; Copa do Mundo; França; Imigração; Identidade.

ABSTRACT: Famous for multicultural profile, the French national football team has had services of several immigrant players throughout the World Cups. This research presents a history highlighting the importance of these who dressed the Bleus shirt throughout the World Cup from the pioneers like Alexandre Villaplane in the 1930 World Cup to the young multicultural generation twice world champion in 2018, passing through Zinedine Zidane, the country's biggest idol and the main player of the world title in 1998. The article also shows the importance that football has for French society, which through the modality manages to discuss and debate sensitive issues of national interest like as immigration, multiculturalism and national identity.

KEYWORDS: Football; World Cup; France; Immigration; Identity. 


\section{INTRODUÇÃO}

Em 1998, a seleção francesa sagrou-se campeã mundial de futebol vencendo o Brasil por 3 a 0 no Stade de France, para delírio dos torcedores. 0 time multicultural, composto por jogadores de diferentes origens étnicas e que simbolizava a sociedade francesa. Triunfava em clima de integração racial para o mundo todo assistir. Vinte anos depois o roteiro se repetiu em gramados russos. Uma jovem equipe ainda mais multicultural do que aquela de duas décadas atrás venceu novamente o principal evento do futebol mundial refletindo de novo a diversificada sociedade francesa. Mas esta história entre imigrantes e descendentes vestindo o uniforme azul começou há muito tempo, mais precisamente na primeira Copa do Mundo em 1930.

Este artigo tem como objetivo mostrar como se desenvolveu esta relação de atletas imigrantes e descendentes com a seleção, e consequentemente, com a sociedade francesa que exprime sentimentos dúbios; ora de fé na integração nacional em momentos vitoriosos, ora de descrença contra a imigração durante as decepções. Também é reforçada nas próximas páginas a importância do futebol como campo de pesquisa sobre temas ligados a imigração, multiculturalismo e identidade.

Mas antes é necessário compreender as primeiras grandes ondas migratórias pelas quais a França passou a partir de meados do século XIX. Entre os anos 1852 e 1870, aproximadamente 1\% da população, cerca de 380 mil pessoas, era composta por estrangeiros que chegavam ao país para suprir deficiências na mão de obra da indústria francesa. Entre 1871 e 1940, houve outra grande leva migratória com órgãos de governo registrando 2,7 milhões de imigrantes, pouco mais de $6 \%$ da população total. ${ }^{1}$

Até este período os estrangeiros eram em sua maioria trabalhadores atraídos por melhores condições de emprego. Aos poucos iam fincando raízes e formando famílias. Nesta época a indústria francesa estava a pleno vapor e não podia ficar sem mão de obra. 0 perfil destes grupos também era parecido: brancos, cristãos e europeus, sendo a maioria formada por belgas, italianos, poloneses, portugueses, espanhóis e armênios.

\footnotetext{
${ }^{1}$ COELHO. Os franceses, p. 38.
} 
Mesmo com essas características e assimilando-se a sociedade francesa, há registros de ataques xenófobos entre o fim do século XIX e início do século XX a estes grupos que trabalhavam na indústria têxtil, em minas de carvão e na agricultura. ${ }^{2}$ Porém, são seus descendentes que "assimilam-se de vez" como franceses:

Filhos de belgas, italianos, poloneses, armênios, espanhóis e portugueses acabaram tornando-se franceses quase que naturalmente e sendo vistos pelos demais franceses como tais. Muitos desses novos franceses oriundos da imigração acabaram até se tornando símbolos da França, tanto em casa como mundo afora. ${ }^{3}$

Ao término da II Guerra Mundial, a Europa passou por um período de reconstrução e crescimento econômico. Na França esse período ficou conhecido como "Os Trinta Gloriosos". ${ }^{4}$ Ao mesmo tempo o perfil do imigrante mudou. Eles não eram mais brancos e de países europeus, agora vinham das antigas colônias sendo especialmente do Magreb e da África Subsaariana. Com o tempo formaram comunidades numerosas, chegando a uma fatia expressiva da população como mostram os números do Instituto Nacional da Estatística e Estudos Econômicos da França (INSEE), principal órgão do governo responsável por coletar, analisar e publicar dados econômicos e sociais: "Segundo o INSEE, até o dia $1^{\text {o }}$ de janeiro de 2014, a população francesa tinha cerca de $11,6 \%$, ou 7,6 milhões de habitantes estrangeiros. Já os descendentes de segunda e terceira geração nascidos na França eram $12 \%$ da população até 2008 de acordo com o mesmo instituto".5

Mesmo sendo um número expressivo, a desigualdade persiste com essa população imigrante ainda bastante marginalizada. Porém, nos campos de futebol a integração entre nativos e estrangeiros é menos problemática. Ao longo das Copas do Mundo, a seleção francesa sempre contou com a participação de jogadores com origem estrangeira, fossem naturalizados ou filhos de imigrantes. Atletas com essas diferentes características étnicas estão presentes no vestiário da seleção francesa há muito tempo.

\footnotetext{
${ }^{2}$ COELHO. Os franceses, p. 38-42.

${ }^{3}$ COELHO. Os franceses, p. 41.

${ }^{4}$ Período que vai de 1945 a 1974.

${ }^{5}$ FREITAS. As seleções de futebol multiculturais da União Europeia, p. 65.
} 
No primeiro Mundial em 1930, a França teve em seu plantel dois jogadores nascidos na Argélia, então colônia francesa: Ernest Liberati e Alexandre Villaplane. Ambos eram Pieds-Noirs, ${ }^{6}$ uma expressão utilizada para designar os franceses que nasciam na Argélia, mas que não tinham descendência árabe. Na maioria das vezes eram filhos de franceses brancos e pobres que imigraram no século XIX em busca de novas oportunidades no país norte africano. ${ }^{7}$

Villaplane foi um dos pioneiros da história do futebol francês, tornando-se em 1926 o primeiro jogador nascido na Argélia a vestir a camisa dos Bleus. Quatro anos depois foi o capitão da seleção na Copa do Mundo. ${ }^{8}$ Entretanto, os diversos problemas em que se envolveu fora dos gramados ofuscaram seus feitos pela seleção nacional. A começar pelo vício nas corridas de cavalo, divertimento em qual gastou boa parte da pequena fortuna que conseguiu acumular com as bonificações recebidas através do futebol. Esse hobby acabou o levando a prisão no fim da década de 1930 após participar de um escândalo de manipulação de resultados. ${ }^{9}$

Mas foi um fato bem mais grave que ofuscou seu pioneirismo no futebol francês. Durante a Segunda Guerra Mundial, Villaplane passou a colaborar com o exército nazista, que na época ocupava a França. Ele extorquia e entregava cidadãos judeus aos alemães e logo depois aderiu à luta armada ao lado de soldados da Gestapo em batalhas no Norte da África, liderando um pelotão chamado Brigade Nord Africain, ${ }^{10}$ famoso por sua crueldade. ${ }^{11}$ Preso pelo exército francês e julgado como traidor, foi fuzilado na manhã do dia 26 de dezembro de 1944 em frente ao Forte de Montrouge em Paris.

Nas Copas seguintes, em 1934 e 1938, a seleção francesa trouxe outros jogadores com origem semelhante a Villaplane e Liberati, como Joseph Alcazar, Joseph Gonzales, Jean Bastien, Michel Brusseaux, Mario Zatelli e Lucien Jasseron, todos Pieds-Noirs. Além deles, outros jogadores filhos de franceses, mas nascidos em outros países da Europa, foram recrutados para atuar com os Bleus.

\footnotetext{
${ }^{6}$ Pés negros (tradução livre).

${ }^{7}$ COELHO. Os franceses, p. 57.

${ }^{8}$ Fèdération française de football. Alexandre Villaplane.

${ }^{9}$ DOYLE. The forgotten story of...the France football captain who murdered for Hitler.

${ }^{10}$ Brigada Norte Africana (tradução livre).

${ }^{11}$ DOYLE. The forgotten story of...the France football captain who murdered for Hitler.
} 
Mas foi na edição do Mundial em 1938 que a França pela primeira vez teve um negro e um magrebino vestindo a camisa da seleção em Copas. Nascido na Guiana Francesa, Raoul Diagne era filho de Blaise Diagne, político senegalês que viria a ser o primeiro deputado negro eleito na França. Mesmo tendo sido educado nos melhores colégios de Paris, optou pelo futebol e teve uma destacada carreira, abrindo as portas aos negros na equipe francesa. ${ }^{12}$ Contemporâneo de Diagne, o argelino Abdelkader Ben Bouali nasceu na região de Sendjas e imigrou para atuar profissionalmente no campeonato francês. Esteve no Mundial de 1938, mas não entrou em campo. ${ }^{13} \mathrm{O}$ primeiro atleta magrebino a defender a seleção francesa foi Ali Benouna em 1936.

Vinte anos depois foi a vez de outros dois atletas multiculturais destacaremse. Filho de imigrantes poloneses que trabalhavam em minas de carvão na região de Noeux, Raymond Kopaszewski, ou simplesmente Kopa, foi um dos melhores jogadores do mundo na década de 1950, tendo sido apelidado de "Napoleão do futebol" por ser baixinho e conquistador de territórios, ${ }^{14}$ além de conquistar a Bola de Ouro em 1958.

Seu companheiro de seleção era filho de pai francês e mãe espanhola, mas nascido em Marrocos. Just Fontaine foi o principal atacante dos Bleus no Mundial de 1958 e até hoje ostenta o recorde de gols marcados em uma só edição de Copas: 13. Após encerrar a carreira precocemente, passou a militar pelos direitos dos jogadores profissionais idealizando ao lado do camaronês Eugène N'Jo Léa a Union nationale des footballeurs professionnels, ${ }^{15}$ o sindicato dos jogadores profissionais franceses.

Com o passar dos anos a liga francesa se internacionalizou, despertando o interesse de jogadores estrangeiros. Ao mesmo tempo, o perfil do imigrante que ia para a França mudava. Cada vez mais chegavam ao país cidadãos oriundos das antigas colônias do Império francês e essa mudança, como não poderia ser diferente, também se refletiu no futebol e na seleção nacional.

Nos anos 1980, a equipe teve sucesso ao ser semifinalista nas Copas de 1982 e 1986 e sagrar-se campeã da Eurocopa em 1984. No elenco, liderado pelo neto de

\footnotetext{
${ }^{12}$ Fèdération française de football. Raoul Diagne.

${ }^{13}$ DJELLIT. Ces Algériens qui ont marqué les Bleus.

${ }^{14}$ GALEANO. Futebol ao sol e a sombra, p. 109.

${ }^{15}$ União nacional dos jogadores de futebol profissionais (tradução livre).
} 
italianos Michael Platini, havia os negros naturalizados Marius Trésor, nascido em Guadalupe, Gérard Janvion, nascido na Martinica e Jean Tigana, nascido no Mali. A partir desta época a seleção francesa passa a ser cada vez mais um selecionado multicultural com imigrantes e descendentes de várias partes do mundo.

\section{O TÍTULO DE 1998 E O TIME BLACK, BLANC ET BEUR}

Ausente dos Mundiais de 1990 e 1994, a França se preparava para sediar o evento em 1998. Promovido de assistente a técnico principal, Aimé Jacquet iniciou um trabalho de renovação na equipe, dando cada vez mais oportunidades para jovens atletas que traziam em seus genes origens estrangeiras.

Após uma consistente campanha na Eurocopa em 1996, quando foi semifinalista e deixou uma boa impressão, a multiétnica seleção nacional ganhou apoio popular. Devido à diversidade étnica que representava a sociedade francesa, o time ganhou o apelido de BBB: black, blanc et beur ${ }^{16}$ encarnando em campo a França multirracial onde os filhos da colonização e os cidadãos nativos se identificavam como franceses através da equipe de futebol. ${ }^{17}$

Porém, nem todos se animaram com o selecionado. Principal liderança da extrema-direita francesa na época, Jean Marie Le Pen chamou a equipe de artificial por ter muitos atletas negros no elenco, afirmando que ela não representava a França. O líder do partido Frente Nacional ainda criticou o fato de alguns jogadores, principalmente os de origem imigrante, não cantarem o hino nacional antes dos jogos. ${ }^{18}$

0 fato de ter uma equipe recheada de atletas com origens imigrantes despertava os mais profundos temores na extrema-direita francesa. Afinal, aqueles vistos como indesejados estariam representando a bandeira da França aos olhos de todo o planeta. Para os extremistas era inadmissível que negros e árabes fossem os protagonistas, porque enxergavam esses atletas como essencialmente uma força

\footnotetext{
${ }_{17}^{16}$ Negro, branco e árabe (tradução livre).

17 GASTAUT. Le métissage par le foot: L'integration, mais jusqu'où?, p. 23.

${ }^{18}$ GASTAUT. Le métissage par le foot: L'integration, mais jusqu'où?, p. 22.
} 
de trabalho provisória, temporária, em trânsito, ${ }^{19}$ embora naquele time a maioria dos atletas fosse nascida em solo francês.

Nas palavras do historiador Paul Dietschy: "aquela seleção era um claro espelho da classe operária francesa que triunfava através do futebol" e para o jornalista Didier Braun, a seleção era nada mais, nada menos do que a "fotografia da população francesa". ${ }^{20} \mathrm{Ou}$ seja, por ora, o multiculturalismo vencia a intolerância e a xenofobia.

As declarações de Le Pen não chegaram a abalar o time que, com o andamento da Copa, passou a conquistar a confiança da mídia e dos torcedores que lotavam os estádios e davam ao evento uma audiência massiva através da transmissão pela TV. ${ }^{21}$

Após vencer seus três primeiros jogos na fase inicial, os franceses sofreram para eliminar o Paraguai com o gol de ouro das oitavas de final e superar uma combativa Itália nas quartas de final apenas nas cobranças de pênaltis. Além de Zidane, outros jogadores com características multiculturais também tiveram participações importantes na inédita conquista. Um deles foi Thuram, jogador que mais vezes vestiu a camisa da seleção na história e hoje é um combativo ativista contra o racismo e a xenofobia na França.

Negro, imigrante e nascido em Guadalupe, Thuram jamais tolerou injustiças contra os imigrantes e descendentes. Contestou publicamente as declarações racistas de Le Pen dizendo que a seleção através de sua diversidade étnica representava sim a verdadeira França. ${ }^{22}$ Nas palavras de Lilian Thuram, lateraldireito titular da seleção, aquela equipe tinha "como maior riqueza sua diversidade cultural". Para o atleta "o título mundial foi fundamental para que os imigrantes e seus descendentes conseguissem expressar melhor suas identidades". ${ }^{23}$ Também criticou através da imprensa o ex-presidente Nicolas Sarkozy, que durante os violentos protestos populares na capital francesa em 2005 chamou de "marginais" jovens negros dos banlieues, a periferia parisiense. Thuram confrontou o então

\footnotetext{
${ }^{19}$ SAYAD. A imigração ou os paradoxos da alteridade, p. 54-55.

${ }^{20}$ Becoming Champions: France: a date with history.

${ }^{21}$ Nos sete jogos da França na Copa do Mundo a média de público no estádio foi de 60 mil torcedores e estima se que mais de 20 milhões de pessoas tenham assistido a final pela TV.

${ }^{22}$ BETING. As melhores seleções estrangeiras de todos os tempos, p. 214.

${ }^{23}$ GASTAUT. Le métissage par le foot: L'integration, mais jusqu'où?, p. 39.
} 
Ministro do Interior lembrando que ele um dia também fora um jovem criado em um banlieue e que não admitia ser ofendido desta forma. ${ }^{24}$ Esse era o retrato desse novo personagem que ganhava cada vez mais a atenção da sociedade.

Na semifinal contra a surpresa Croácia, o triunfo só veio com dois gols salvadores desse herói improvável. A consagração viria com um resultado que nem o francês mais otimista esperava: uma goleada de 3 a 0 sobre a poderosa seleção brasileira. Uma vitória que impactou o país de uma forma jamais vista em decorrência de um evento esportivo.

Quando o árbitro Said Belqola apitou o fim da partida no Stade de France, o país inteiro explodiu em êxtase. Cerca de um milhão de franceses tomaram a famosa avenida Champs Elysées em Paris para celebrar. Segundo o jornalista John Carlin foi a maior celebração festiva vista em Paris desde a libertação dos nazistas em 1944 durante a Segunda Guerra Mundial. ${ }^{25}$

Pessoas que jamais haviam se encontrado e nem se conheciam estavam juntas no meio da rua, em um claro exemplo da teoria de comunidade imaginada de Anderson, onde os membros desse grupo firmam uma camaradagem entre si tendo em mente uma imagem de comunhão entre todos. ${ }^{26}$ Além de bandeiras francesas era possível avistar também bandeiras dos países das antigas colônias, representadas no time nacional pelos filhos da imigração. A festa era de todos em uma grande expressão de pluralidade cultural como afirma Giulianotti:

Todavia, as identidades nacionais nunca são estáticas nem mononucleares. Há uma multiplicidade de identidades nacionais em qualquer nação, distinguíveis ao longo de linhas estruturais específicas ou de linhas ideológicas, tais como aquelas relacionadas à religião, à classe, à etnia e à identificação com um soberano específico. Em sociedades multiculturais, a heterogeneidade das vozes nacionalistas é particularmente conspícua. ${ }^{27}$

\footnotetext{
${ }^{24}$ FREITAS; TRIGO; ALMEIDA. Diferenças culturais e identitárias na França através do ultras do Paris Saint Germain, p. 90.

${ }^{25}$ BECOMING CHAMPIONS: France: a date with history.

26 ANDERSON. Comunidades imaginadas: Reflexões sobre a origem e a difusão do nacionalismo, p. 32.

${ }^{27}$ GIULIANOTTI. Sociologia do futebol: dimensões históricas e socioculturais do esporte das multidões, p. 53.
} 
Dos 22 campeões mundiais em 1998, 14 tinham origem estrangeira de diferentes partes do mundo. Havia os nascidos em antigas colônias como Lilian Thuram, Christian Karembeu e Patrick Vieira e os membros da segunda geração de imigrantes, como Zinedine Zidane, Thierry Henry, Youri Djorkaeff, Bernard Lama, Bernard Diomède, Alain Boghossian, David Trezeguet, Bixente Lizarazu, Robert Pires e Vicent Candela, além de Marcel Desailly que nasceu em Gana e se naturalizou.

Protagonista na final contra o Brasil e grande craque da equipe, Zidane era uma das figuras que representava essa união nacional. 0 camisa 10 nascido no subúrbio de Marselha e filho de imigrantes argelinos era o mais novo herói da pátria. Autor de dois gols na decisão contra o Brasil foi o atleta mais celebrado pelos torcedores após a conquista da Copa do Mundo. Discreto fora dos gramados e avesso a badalação, o jogador chegou até a ter seu nome ovacionado pelos fãs que cantavam "Zidane presidente" para desgosto de Le Pen. ${ }^{28}$

Seis décadas antes da vitória francesa, Diagne iniciava a história dos negros na seleção, porém, sua realidade era totalmente diferente de seus sucessores. Ele era filho de um diplomata e durante a juventude estudou em ótimas escolas, tendo um padrão de vida elitizado, ${ }^{29}$ algo totalmente diferente da realidade encontrada pelos negros campeões do mundo em 1998. Thuram, Henry, Vieira e companhia viveram nas periferias e tiveram que driblar, além dos rivais, as dificuldades que essas populações encontravam pelo caminho.

E ainda encontram. Em 2018, quando Kylian Mbappé marcou o quarto gol francês aos 20 minutos do segundo tempo e praticamente sacramentou a vitória dos Bleus sobre a Croácia na final da Copa, uma talentosa e promissora geração de futebolistas colocava novamente a França no topo do mundo. Mais uma vez um time multicultural formado por jovens nascidos nas periferias francesas e que há 20 anos eram apenas crianças que celebravam a conquista da seleção, trazia a tona de novo a questão da integração, da imigração e do multiculturalismo.

Mbappé, o único membro do time bicampeão mundial nascido após a conquista no Stade de France em 1998, é um exemplo de como a integração dos imigrantes e descendentes pouco avançou depois da festa do time BBB. Filho de

\footnotetext{
${ }^{28}$ GALEANO. Futebol ao sol e a sombra, p. 123.

${ }^{29}$ KSSIS-MARTOV. Raoul Diagne: I'homme à tout faire du Racing...
} 
um imigrante camaronês e uma argelina descendente de imigrantes, o jovem cresceu na região de Bondy, um banlieue de Paris, tendo enfrentado dificuldades como qualquer outro jovem da periferia parisiense.

Nova joia do futebol francês, Mbappé foi um dos campeões mundiais que passaram pelo Centro de Treinamento de Clairefontaine, uma academia de excelência localizada nos arredores de Paris que recruta jovens com potencial. No moderno CT, inaugurado em 1988, garotos com idade entre 13 e 15 anos passam por um período de testes, treinamentos e estudos quando não estão no gramado. Clairefontaine foi bastante comentado pela imprensa internacional ao longo do Mundial de 2018, citado como sendo modelo de formação e integração através do esporte.

Além de Mbappé outros jogadores como Paul Pogba, N'Golo Kanté e Blaise Matuidi, tornaram-se símbolos dessa equipe. Kanté inclusive ajudava o pai aos sete anos de idade recolhendo o lixo deixado nas ruas de Paris pela festa do título mundial no dia 12 de julho de $1998 .^{30}$ Um time que ficou marcado pela disciplina tática e também pela maturidade de saber evitar que os temas externos atrapalhassem a concentração da seleção que cantou "A Marselhesa" em todas as partidas e quando foi recebida na volta para casa pelo presidente Emmanuel Macron no Palácio do Eliseu, ${ }^{31}$ não dando munições para insinuações da extrema-direita.

Hoje em dia é mais fácil encontrar imigrantes e descendentes em postos de trabalho subqualificados ao invés de cargos de gerência ou chefia. ${ }^{32}$ Estudantes de famílias imigrantes mais bem estruturadas e integradas socialmente à cultura francesa atingem desempenho superior no meio acadêmico em relação a jovens imigrantes e descendentes de condição social mais baixa. ${ }^{33}$ Isso em um país onde $15 \%$ da população total têm pelo menos um de seus pais nascidos fora do

\footnotetext{
${ }^{30}$ LOZETTI. Herói sem luxo da França, Kanté colheu lixo das ruas de Paris no título de 98.

${ }^{31}$ CHANTEGRELET. Les champions du monde ont mis le feu à l'Elysée!

${ }^{32}$ FAUGĖRE; BOUVET. L'accès à un travail et des conditions d'emploi plus difficiles pour les immigrés, p.1-2.

${ }^{33}$ CAILLE et al. La réussite scolaire des enfants d'immigrés au collège est plus liée au capital culturel de leur famille qu'à leur passé migratoire, p.87.
} 
território francês ${ }^{34}$ e em que sua Constituição proíbe diferenciar seus cidadãos segundo raça, origem ou religião. ${ }^{35}$

Atentados terroristas que aconteceram na França nos últimos anos não foram provocados, em sua grande maioria, por estrangeiros, mas sim por jovens de origem estrangeira e muçulmana, porém, nascidos e criados na França. São indivíduos pouco integrados a sociedade e que encontram pequenas perspectivas de ascensão social. Em alguns casos, membros desses grupos étnicos buscam assumir uma origem estrangeira ou dos antepassados como forma de identidade, definida por Vermeulen como uma "etnicidade reativa". ${ }^{36}$

O Instituto Nacional de Estudos Demográficos (INED) fez uma pesquisa em parceria com o INSEE em 2008 e 2009, ouvindo 22 mil pessoas e concluindo que existem dificuldades de integração na sociedade da França devido a preconceitos e estereótipos. ${ }^{37}$ Membros da segunda e terceira geração de imigrantes sentem-se cidadãos do país, mas os franceses nativos não os veem dessa forma, o que acaba gerando uma crise de identidade. ${ }^{38}$

A marginalização e ações terroristas cometidas por estes jovens acabam fortalecendo o discurso radical e ultranacionalista da extrema-direita francesa, hoje liderada por Marine Le Pen, sobrinha de Jean Marie. Um comportamento que acaba colocando o imigrante como principal problema da sociedade.

\section{A tenSA E hiSTóRICA RELAÇão ENTRE FranÇA E ARGÉlia}

Os argelinos são o grupo imigrante mais populoso da França. Colônia francesa desde 1830, quando foi invadida e conquistada, a Argélia atraiu durante muitos anos a atenção de trabalhadores europeus, especialmente franceses chamados de Pieds-Noirs e que se aproveitaram da moderna infraestrutura das principais cidades argelinas para ganhar dinheiro.

\footnotetext{
${ }^{34}$ BREUIL-GENIER; BORREL; LHOMMEAU. Les immigrés, les descendants d'immigrés et leurs enfants, p. 36.

${ }^{35}$ POUTIGNAT; STREIFF-FERNART. Teorias da etnicidade: seguido de grupos étnicos e suas fronteiras de Frederik Barth, p. 16.

${ }^{36}$ VERMEULEN. Imigração, integração e a dimensão política da cultura, p. 138.

${ }^{37}$ FREITAS. As seleções de futebol multiculturais da União Europeia, p. 40.

${ }^{38}$ LORENZO. Le racisme en France étudié à la loupe: se sentir Français mais ne pas l'être pour les autres.
} 
Enquanto isso, no interior e na região rural da Argélia havia pouco desenvolvimento. Os locais eram habitados majoritariamente pela população nativa e de origem árabe. Com o empobrecimento e falta de perspectivas, parte desses argelinos mudou-se para a metrópole no final do século XIX, onde foram atuar como operários. Segundo arquivos do Musée National de L'histoire de L'immigration, ${ }^{39}$ esses homens eram obrigados a retornar a Argélia após um período de trabalho, sendo substituídos por outros. Havia a preocupação do governo francês que este tipo de imigrante, que era considerado como indesejado, pudesse permanecer e criar laços com o país. Mesmo tendo nacionalidade francesa, eram tidos como cidadãos de segunda classe já que não tinham os mesmos direitos que os nativos franceses e estavam expostos a uma rigorosa lei de trabalho. ${ }^{40}$

No começo do século XX já existia uma crescente população argelina na França, porém, eles não tinham status específico. Poderiam ser encaixados no conceito do pária de Varikas, que classifica essas pessoas como figuras de condição social que combinam exclusão com desprezo. ${ }^{41}$ Estatísticas do governo na década de 1900 já mostravam milhares deles vivendo nas principais cidades francesas:

No Censo de 1901, eles não são distinguidos dos franceses, mas aparece a menção de "trabalhadores da Argélia". Eles permanecem muito atrás dos migrantes europeus. Um levantamento de 1912 contabiliza de 4 a 5.000 argelinos na França metropolitana, incluindo mil na capital e em sua periferia. Eles não são apenas parte do sistema de salários agrícolas, mas também pertencem ao proletariado industrial e urbano. Eles trabalham, por exemplo, na refinaria de Say, nas empresas de ônibus e nas metrópoles de Paris, nas fábricas Michelin, nas minas de Pas-deCalais, nas indústrias de Lyon, nas docas do Porto de Marselha. ${ }^{42}$

\footnotetext{
${ }^{39}$ Museu Nacional da História da Imigração (tradução livre).

${ }^{40}$ Musée National de L'histoire de L'immigration - l'immigration algérienne en France.

${ }^{41}$ VARIKAS. A escória do mundo: figuras do pária, p. 76.

42 "Lors du recensement de 1901, ils ne sont pas distingués des Français mais apparaît la mention de "travailleurs originaires d'Algérie". Ils restent bien loin derrière les migrants européens. Une enquête de 1912 comptabilise 4 à 5000 Algériens en métropole dont un millier dans la capitale et sa périphérie. Ils ne font plus seulement partie du salariat agricole, mais appartiennent aussi au prolétariat industriel et urbain. Ils travaillent par exemple à la raffinerie Say, à la Compagnie des Omnibus et sur les chantiers du métropolitain à Paris, les usines Michelin, dans les mines du Pas-de-Calais, les industries lyonnaises, sur les docks du port de Marseille" (tradução nossa). Musée National de L'histoire de L'immigration - l'immigration algérienne en France.
} 
O número de imigrantes argelinos explodiu alguns anos depois do fim da Segunda Guerra Mundial. Com necessidade de mão de obra para ajudar em sua reconstrução, a França decidiu novamente recrutar trabalhadores argelinos que atingiram o número de 350 mil indivíduos no país em 1962 segundo dados do Musée National de L'histoire de L'immigration. ${ }^{43}$ Neste mesmo ano chegou ao fim a violenta guerra pela Independência da Argélia iniciada em 1954, que terminou com a libertação do Estado africano após mais de um século de domínio francês.

A imigração argelina para a França foi um típico caso de imigração de trabalho que se tornou uma imigração de povoamento. ${ }^{44}$ Isso já havia ocorrido com italianos e poloneses, por exemplo, entre o fim do século XIX e começo do século XX. Essa imigração de povoamento acontece quando os primeiros estrangeiros chegam a um novo país exclusivamente para trabalhar e espera-se que retornem algum dia para seu local de origem. Porém, com o passar do tempo, algumas situações evitam que estes imigrantes regressem, como, por exemplo, a criação dos filhos nascidos no novo país, as incertezas da situação da terra natal e as mudanças de leis que podem favorecer sua permanência. ${ }^{45}$ Sayad afirma que esta é uma regra geral dos movimentos migratórios:

[...] toda a imigração de trabalho contém em germe a imigração de povoamento que a prolongará; inversamente, pode-se dizer que não há imigração reconhecida como de povoamento (com exceção talvez dos deslocamentos de populações que a colonização requer ou ainda dos movimentos de populações consecutivos ao estado de guerra ou aos remanejamentos de fronteiras) que não tenha começado com uma imigração de trabalho. ${ }^{46}$

Atualmente a população de indivíduos oriundos da Argélia é a maior parcela de imigrantes vivendo na França. Uma pesquisa feita em 2012 pelo INSEE concluiu que há 748 mil argelinos no país, que correspondem a 13,1\% de todos os estrangeiros residentes em território francês. ${ }^{47}$ Os descendentes de imigrantes

\footnotetext{
${ }^{43}$ Musée National de L'histoire de L'immigration - l'immigration algérienne en France.

${ }^{44}$ SAYAD. A imigração ou os paradoxos da alteridade, p. 67.

${ }^{45}$ FENTON. Etnicidade, p.151-152

${ }^{46}$ SAYAD. A imigração ou os paradoxos da alteridade, p. 67.

${ }^{47}$ INSEE. Étrangers - Immigrés.
} 
nascidos na França engrossam os números da colônia argelina no país com cerca de 617 mil membros. ${ }^{48}$

Modalidade esportiva mais popular e presente na cultura de massas, o futebol também tem uma relação antiga entre franceses e argelinos. Foi no dia 09 de fevereiro de 1936 que pela primeira vez um jogador de origem árabe vestiu a camisa da seleção francesa. 0 zagueiro argelino Ali Benouna pisou no gramado do estádio do Parc de Princes para enfrentar a Tchecoslováquia e abriu as portas para outros magrebinos. ${ }^{49}$

Na década 1950 já havia jogadores imigrantes ou de origem africana atuando na liga francesa. Esses atletas defendiam clubes franceses, mas mantinham vínculos com a Argélia e alguns foram personagens importantes no processo de independência do país africano integrando um selecionado internacional de futebol.

Casos de Rachid Mekhloufi e Mustapha Zitouni. Argelinos de nascimento foram convocados para a seleção francesa meses antes da Copa do Mundo de 1958. Provavelmente estariam no time que seria semifinalista no Mundial daquele ano, mas optaram por recusar a convocação em prol da luta de independência argelina. Ambos fugiram da França e passaram a integrar a seleção internacional da Frente de Libertação Nacional, 50 um partido político argelino de orientação socialista que lutava pelo fim do colonialismo francês e pela independência da Argélia.

O esporte foi uma ferramenta encontrada pelo FLN, que resolveu montar uma equipe com vários jogadores magrebinos de destaque no futebol francês para dar visibilidade à luta pela independência. E os resultados não aconteceram apenas dentro de campo, onde a seleção atuou 91 vezes em quatro anos contra países simpatizantes a causa argelina, como também fora das quatro linhas, gerando repercussão dentro da França, onde cidadãos descontentes com a guerra e as mortes exigiam uma solução do governo para encerrar o conflito. ${ }^{51}$

Décadas depois o futebol novamente seria utilizado como instrumento político, só que dessa vez visando a pacificação entre franceses e argelinos. No dia

\footnotetext{
${ }^{48}$ INSEE. Être né en France d'un parent immigré.

${ }^{49}$ FÉDÉRATION FRANÇAISE DE FOOTBALL. Ali Benouna.

${ }^{50}$ BILLEBAULT. Rachid Mekhloufi: "Je n'ai pas hésité avant de rejoindre l'équipe du FLN algérien".

${ }^{51}$ RAMONET. Football et passions nationales, p. 55-56.
} 
06 de outubro de 2001 os dois países se enfrentaram no Stade de France, em Paris. Seria o primeiro confronto entre os dois países na história, mas o jogo também gerou dúvidas identitárias entre os descendentes de imigrantes argelinos. Para quem torcer: a seleção do país de nascimento ou a pátria dos antepassados?

O encontro é uma oportunidade para se concentrar no sentimento de identidade franco-argelina vivida de forma muito diferente dependendo do passado pessoal. De certa forma, esta é a escolha final: quem colocar em primeiro lugar em seu coração? O país que é seu hoje ou de seus antepassados? Graças a este jogo, todos estão convencidos de que saberemos mais sobre a integração das populações de origem imigrante. ${ }^{52}$

Esse jogo de identidade, ${ }^{53}$ que é quando existe um conflito ou cruzamento de identidade e onde não existe uma identidade única, acontece devido história de alguns países que tiveram culturas distintas sendo unificadas através da violência por um longo período de conquista, suprimindo diferenças culturais e buscando unir à força diferentes classes sociais e grupos étnicos, ${ }^{54}$ caso da relação entre franceses e argelinos.

A partida foi marcada pela tensão e animosidade nas arquibancadas onde estavam milhares de argelinos e seus descendentes. 0 hino francês foi vaiado e a seleção francesa insultada incessantemente. A França caminhava para uma vitória tranquila, mas aos 30 minutos do segundo tempo o jogo foi interrompido após torcedores invadirem o gramado empunhando bandeiras argelinas.

A repercussão do jogo para a comunidade argelina foi extremamente negativa. A imprensa não aliviou nas críticas chamando os torcedores de "selvagens" e políticos da extrema-direita como Jean Marie Le Pen manifestaramse contrários à política de integração, colocando a culpa pelo fiasco do amistoso nos imigrantes. ${ }^{55}$

\footnotetext{
52 "La rencontre est l'occasion d'une mise au point sur le sentiment identitaire franco-algérien au vécu très varie em fonction des parcours personnels. D'une certaine façon, II s'agit du choix ultime: qui placer d'abord dans son cœur? Le pays qui est le vôtre aujourd'hui ou celui de vos ancêtre? Grâce à ce match, tout le monde est persuade qu'on en saura davantage sur l'intégration des populations issues de l'immigration". (tradução nossa). GASTAUT. Le métissage par le foot: L'integration, mais jusqu'où?, p. 126.

${ }^{53}$ HALL. A identidade cultural na pós-modernidade, p. 14-15

${ }^{54}$ HALL. A identidade cultural na pós-modernidade, p. 35-36

${ }^{55}$ GASTAUT. Le métissage par le foot: L'integration, mais jusqu'où?, p. 144-147.
} 
Um comportamento comum de grandes grupos nacionais que lamentam a perda do status de grandeza de outrora devido à chegada de personagens diferentes ao seu território, chamados de outsiders por Elias e Scotson. ${ }^{56}$ Por isso, para manter seu status, esse grupo procura atacar, estigmatizar e rejeitar qualquer outro indivíduo que pertença a uma origem, etnia ou cultura diferente. No amistoso do Stade de France em 2001 foram os argelinos e seus descendentes os outsiders da vez.

Marie-George Buffet, então ministra da Juventude e dos Esportes da França, afirmou que lembrará para sempre da partida como um grande fracasso e Thuram, que estava em campo naquele dia, disse que torcedores foram inconsequentes, já que seus atos seriam utilizados politicamente por grupos contrários aos imigrantes. ${ }^{57}$

E de fato serviram como munição para os críticos do multiculturalismo e da imigração, que contestavam a presença do grande número de atletas com este perfil no elenco. Dez anos depois do amistoso, uma conversa do então técnico da seleção Laurent Blanc com dirigentes da Federação Francesa de Futebol foi flagrada por um site jornalístico independente. Eles discutiam a criação de uma cota para jogadores de origem imigrante nas seleções de base e nos centros de formação para jovens, postura claramente xenófoba e prejudicial às medidas de integração através do esporte. 58

A relação entre magrebinos e franceses continua tensa até hoje. Atentados terroristas cometidos por jovens franceses radicalizados e o medo da vinda de mais imigrantes alimentam cada vez mais o fantasma da xenofobia na sociedade e também a extrema-direita, que chegou ao segundo turno das eleições presidenciais de 2017 com Marine Le Pen.

No futebol a relação entre a França e seus imigrantes oscila entre o amor e o ódio, principalmente em épocas de Copa do Mundo. A geração campeã mundial em 1998 fracassou na Copa seguinte, tendo sido rotulada pela imprensa e torcida como mercenária e individualista. ${ }^{59}$ No Mundial de 2010 aconteceu um dos casos

\footnotetext{
${ }^{56}$ ELIAS; SCOTSON. Os estabelecidos e os outsiders: sociologia das relações de poder a partir de uma pequena comunidade, p. 45.

${ }^{57}$ LES BLEUS: une autre histoire de France.

${ }^{58}$ GIRARD. Des quotas de Blancs en équipe de France?

${ }^{59}$ GASTAUT. Le métissage par le foot: L'integration, mais jusqu'où?, p. 162-163.
} 
mais polêmicos da história recente do futebol francês com uma eliminação na primeira fase marcada por brigas internas entre atletas e o técnico Raymond Domenech, jogadores se recusando a treinar e a expulsão de Nicolas Anelka da delegação ainda durante o evento. Um prato cheio para críticas da imprensa, políticos e torcedores. Novamente os atletas de origem estrangeira eram taxados de problemáticos e que não representavam o país e o cidadão francês.

Em 2015 foi a vez do filho de imigrantes argelinos Karim Benzema, ser afastado da seleção por problemas disciplinares, acusando o técnico Didier Deschamps de "ceder a pressão de grupos racistas" 60 para sacá-lo da equipe, algo que também colaborou para que a animosidade entre franceses e imigrantes continue presente e esteja cada vez mais distante e incerta de uma solução

Passados 20 anos entre a conquista dos dois títulos mundiais, pouca coisa mudou nas políticas de integração das populações imigrantes. Como afirma Gastaut, "o mesmo país que foi capaz de unir as diferenças de sua população através da vitória no futebol, também pode passar ao mundo a imagem que o radicalismo e xenofobia ainda estão presentes em sua sociedade". ${ }^{61}$

\section{CONSIDERAÇõES FINAIS}

Na França o futebol foi aos poucos se tornando o esporte mais popular. Para a população mais pobre e os imigrantes, tornou-se uma válvula de escape. Ele também funciona como um termômetro, medindo a temperatura da sociedade em temas delicados como patriotismo, identidade nacional e imigração em épocas de Copa do Mundo. A gangorra de sentimentos alterna entre o positivismo da integração nacional e harmonia racial nas vitórias, com a sensação de negativismo em momentos de derrotas e decepções onde o descendente de imigrantes é sempre um imprestável, um antipatriota por se negar a cantar "A Marselhesa" antes das partidas.

\footnotetext{
${ }^{60}$ POLO. Benzema: "Deschamps se pliega a la presión de una parte racista de Francia".

${ }^{61}$ GASTAUT. Le métissage par le foot: L'integration, mais jusqu'où?, p. 126-128.
} 
Por mais que o senso comum classifique o futebol como sendo um instrumento de alienação social, ${ }^{62}$ ele tem uma grande importância histórica, política e social entre os franceses, pois a seleção consegue expor através de seus jogadores sua diversidade étnica e contribui dessa forma para um debate sobre preconceitos da sociedade. ${ }^{63}$

Se o torcedor se identifica com um clube por causa da história, origem, influência familiar ou outros motivos, com a seleção nacional a identificação se dá pelo fator da nacionalidade, já que esta equipe representa seu país. E a seleção francesa de futebol é um dos melhores exemplos de representação social, já que ali estão presentes personagens de distintas origens étnicas e imigrantes, diferentemente de diversos outros setores da sociedade, onde as minorias são raramente representadas e tem poucas chances de obter sucesso. ${ }^{64}$

Os times campeões mundiais em 1998 e 2018, que levaram milhões de pessoas para celebrar na Champs Elysées, refletiam a sociedade multicultural do país onde cidadãos negros, brancos e árabes sentiram-se representados e reconhecidos. Sentiam-se de alguma forma pertencentes àquele momento, àquela comunidade imaginada idealizada por Anderson. $65 \mathrm{Ou}$ sentiam-se membros da verdadeira França, como Thuram afirmou após vencer o Mundial. ${ }^{66}$ Como citou Antoine Griezmann na entrevista coletiva após a final da Copa de 2018, a "seleção francesa campeã é uma equipe com atletas de diferentes origens, mas unida e sendo a França que as pessoas amam". 67

Como mostrado nas páginas anteriores, a participação de jogadores estrangeiros ou de descendência imigrante foi de suma importância para a história do futebol francês ao longo das Copas do Mundo. É impossível ignorar a relevância destes atletas e sem eles o futebol francês seria bem menor. Talvez estivesse até hoje perseguindo seu primeiro título mundial.

\footnotetext{
${ }^{62}$ MARCUSE. Cultura e Sociedade, p. 183.

${ }^{63}$ STASI. Le football: aventure personnelle et phénomène de société, p. 131.

${ }^{64}$ FREITAS. As seleções de futebol multiculturais da União Europeia, p. 54.

${ }^{65}$ ANDERSON. Comunidades imaginadas: Reflexões sobre a origem e a difusão do nacionalismo, p. 32.

${ }^{66}$ GASTAUT. Le métissage par le foot: L'integration, mais jusqu'où?, p. 6.

${ }^{67}$ PÉCOUT. Coupe du monde 2018 : Antoine Griezmann, un héraut plutôt qu'un héros.
} 
A França, e a Europa em geral, não podem mais acreditar que são culturas homogêneas, porque dentro de suas fronteiras concentram uma vasta diversidade, seja étnica, cultural, linguística e religiosa. ${ }^{68}$ Dentro de campo ou fora das quatro linhas, a seleção nacional continuará gerando importantes debates populares sobre a questão do multiculturalismo e da imigração na sociedade francesa, mostrando como o campo esportivo pode muito bem ser mais um espaço para aprofundar estas discussões e novos estudos. ${ }^{69}$

\section{REFERÊNCIAS}

ANDERSON, Benedict. Comunidades imaginadas: Reflexões sobre a origem e a difusão do nacionalismo. São Paulo: Companhia das Letras, 2008.

BECOMING CHAMPIONS: France: a date with history. Direção: Fernando Kalife. México, 2018, 41 min., son., colorido.

BETING, Mauro. As melhores seleções estrangeiras de todos os tempos. São Paulo: Contexto, 2010.

BILLEBAULT, Alexis. Rachid Mekhloufi: “Je n'ai pas hésité avant de rejoindre l'équipe du FLN algérien". Le Monde, Paris. 01 abr. 2016. Disponível em: https://lemde.fr/2BZSijD. Acesso em: 13 maio 2018.

BOURDIEU, Pierre. Como é possível ser esportivo? In: Questões de sociologia. Rio de Janeiro: Marco Zero, 1983, p. 136-163.

BREUIL-GENIER, Pascale; BORREL, Catherine; LHOMMEAU, Bertrand. Les immigrés, les descendants d'immigrés et leurs enfants. Insee: vue d'ensemble portrait de la population. France, Portrait Social - édition 2011, p. 33-39, 2011.

CAILLE Jean-Paul; COSQUÉRIC Ariane; MIRANDA Émilie; VIARD-GUILLOT, Louise. La réussite scolaire des enfants d'immigrés au collège est plus liée au capital culturel de leur famille qu'à leur passé migratoire. Insee Références Dossier. France, Portrait Social, p. 87-106, 2016.

CHANTEGRELET, Adrien. Les champions du monde ont mis le feu à l'Elysée! Le Parisien, Paris. 16 jul. 2018. Disponível em: https://bit.ly/2QlfXDT. Acesso em: 19 jul. 2018.

COELHO, Ricardo Correa. Os franceses. São Paulo: Contexto, 2010.

DJELLIT, Nabil. Ces Algériens qui ont marqué les Bleus. France Football, Paris. 27 mar. 2015. Disponível em: https://bit.ly/2QHFWF0. Acesso em: 08 maio 2018.

\footnotetext{
${ }^{68}$ HABERMAS. Sobre a Constituição da Europa, p. 85.

${ }^{69}$ BOURDIEU. Questões de sociologia, p. 138.
} 
DOYLE, Paul. The forgotten story of...the France football captain who murdered for Hitler. The Guardian, Londres. 16 nov. 2009. Disponível em: https://bit.ly/2SEpO4A. Acesso em: 07 maio 2018.

ELIAS, Norbert; SCOTSON, John L. Os estabelecidos e os outsiders: sociologia das relações de poder a partir de uma pequena comunidade. Rio de Janeiro: Jorge Zahar Editora, 2000.

FAUGÈRE, Anthony; BOUVET, Sandra. L'accès à un travail et des conditions d'emploi plus difficiles pour les immigrés. Insee Analyses Auvergne-RhôneAlpes, n. 22, p. 1-4, septembre 2016.

FÉDÉRATION FRANÇAISE DE FOOTBALL. Alexandre Villaplane. Disponível em: https://bit.ly/2Qn8m7Z. Acesso em: 04 maio 2018.

FÉDÉRATION FRANÇAISE DE FOOTBALL. Ali Benouna. Disponível em: https://bit.ly/2Gb7vT5. Acesso em: 05 maio 2018.

FÉDÉRATION FRANÇAISE DE FOOTBALL. Raoul Diagne. Disponível em: https://bit.ly/2RMUH6X. Acesso em: 05 maio 2018.

FENTON, Steve. Etnicidade. Lisboa: Instituto Piaget, 2003.

FREITAS, Guilherme Silva Pires de. As seleções de futebol multiculturais da União Europeia. Mestrado em Estudos Culturais (Dissertação). Escola de Artes, Ciências e Humanidades da USP, São Paulo, 2017.

FREITAS, Guilherme Silva Pires de. Quem são os jogadores multiculturais das seleções europeias na Copa de 2018. Disponível em: https://bit.ly/2QuNRpM. Acesso em: 27 jun. 2018.

FREITAS, Guilherme Silva Pires de; TRIGO, Luiz Gonzaga Godoi; ALMEIDA, Marco Betinne. Diferenças culturais e identitárias na França através do ultras do Paris Saint Germain. Revista Brasileira de Estudos do Lazer, v. 4, n. 2, p. 80-98, maio-ago. 2017.

GALEANO, Eduardo. Futebol ao sol e a sombra. Porto Alegre: L\&PM Pocket, 2013. GASTAUT, Yvan. Le métissage par le foot: L'integration, mais jusqu'où? Paris: Éditions Autrement, 2008.

GIRARD, Quentin. Des quotas de Blancs en équipe de France? Libération, Paris 29 abr. 2011. Disponível em: https://bit.ly/2G5uhvu. Acesso em: 18 maio 2018.

GIULIANOTTI, Richard. Sociologia do futebol: dimensões históricas e socioculturais do esporte das multidões. São Paulo: Nova Alexandria, 2010.

HABERMAS, Jürgen. Sobre a Constituição da Europa. São Paulo: Editora UNESP, 2012.

HALL, Stuart. A identidade cultural na pós-modernidade. Rio de Janeiro: Lamparina, 2014.

INSEE. Étrangers - Immigrés. Disponível em: https://bit.ly/2G8zltO. Acesso em: 02 maio 2018.

INSEE. Être né en France d'un parent immigré. Disponível em: https://bit.ly/2zOOxvY. Acesso em: 02 maio 2018. 
KSSIS-MARTOV, Nicolas. Raoul Diagne: I'homme à tout faire du Racing... So Foot, Paris. 11 out. 2015. Disponível: https://bit.ly/2C0DnFZ. Acesso em: 08 maio 2018.

LES BLEUS: une autre histoire de France. Direção: David Dietz, Sonia Dauger, Pascal Blanchard. França, 2016, 103 min., son., colorido.

LORENZO, Sandra. Le racisme en France étudié à la loupe: se sentir Français mais ne pas l'être pour les autres. Huffington Post, Paris. 08 jan. 2016. Disponível em: https://bit.ly/1UG5OsY. Acesso em: 29 abr. 2018.

LOZETTI, Alexandre. Herói sem luxo da França, Kanté colheu lixo das ruas de Paris no título de 98. Globo.com, Istra. 12 jul. 2018. Disponível em: https://glo.bo/2JhLjDd. Acesso em: 13 out. 2018.

MARCUSE, Herbert. Cultura e Sociedade, v. 1. Rio de Janeiro: Paz e Terra, 1997.

MUSÉE NATIONAL DE L'HISTOIRE DE L'IMMIGRATION - I'immigration algérienne en France. Disponível em: https://bit.ly/2QK0I6V. Acesso em: 14 maio 2018.

PÉCOUT, Adrien. Coupe du monde 2018 : Antoine Griezmann, un héraut plutôt qu'un héros. Le Monde, Paris. 16 jul. 2018. Disponível em: https://lemde.fr/2Ur451P. Acesso em: 19 jul. 2018.

POLO, Pablo. Benzema: "Deschamps se pliega a la presión de una parte racista de Francia". Marca, Madri. 01 jun. 2016. Disponível em: https://bit.ly/2B6HIFI. Acesso em: 14 out. 2018.

POUTIGNAT, Philippe; STREIFF-FERNART, Jocelyne. Teorias da etnicidade: seguido de grupos étnicos e suas fronteiras de Frederik Barth. São Paulo: Editora UNESP, 2011.

RAMONET, Ignacio. Football et passions nationales. In: Géopolitique du Football. Bruxelles: Editions Compelxe, 1998, p. 55-62.

SAYAD, Abdelmalek. A imigração ou os paradoxos da alteridade. São Paulo: EdUSP, 1998.

STASI, Bernard. Le football: aventure personnelle et phénomène de société. In: Géopolitique Du Football. Bruxelles: Editions Complexe, 1998, p. 127-132.

VARIKAS, Eleni. A escória do mundo: figuras do pária. São Paulo: Editora UNESP, 2014.

VERMEULEN, Hans. Imigração, integração e a dimensão política da cultura. Lisboa: Edições Colibri, 2001. 